\title{
Effect of Diodo Laser Irradiation on Instrumented Root Canal Walls: A Scanning Electron Microscopy and Histologic Preliminary Study.
}

\author{
Aguilar Cuevas Marcela A,* Villarreal de Justus Yolanda,* Antuna Bizarro Silvia** and García \\ Garduño Margarita V.*** \\ *Universidad Tecnológica de México S.C. Clínica de Endodoncia, Azcapotzalco C.P. 2870 \\ ** Depto.de Biología Celular y Tisular, Facultad de Medicina, UNAM. Coyoacan C.P. 0100 \\ *** Lab. de Biomateriales, Facultad de Odontología, UNAM. Coyoacán C.P. 0100 México D.F.
}

Since the development of the ruby laser by Maiman in 1960, different lasers have been studied in a variety of dental applications. The purpose of the study was to evaluated in vitro, the cleansing and morphological changes in root canal walls as a result of intracanal irradiation by Diodo laser. One of fundamental aims of root canal treatment is clean the root canal as thoroughly as possible to eliminate tissue debris and microorganisms so that obturation results in eny leakage [1]. Each laser has distinct characteristics and properties. The effect of irradiation on target tissue is largely dependent on laser wavelength and tissue absorption [2]. $\mathrm{Nd}$ :Yag, $\mathrm{Co}_{2}$, and argon lasers have been demostrated to be capable of vaporizing debris in root canal treatment by varying the energy level and duration [3].

Twelve human teeth with a single root canal were selected for this study. Root canals were prepared with the Crown Down technique. They were sectioned longitudinally and divided in two groups. In the group wich served as a control, the teeth were not lased. The teeth of the lased group were irradiated by an Laser Diodo Opus 5 with $810-850 \mathrm{~nm}$ of wavelength, 2.4 watts, and pulse duration and pulse frequency fixed at $0.05_{\mathrm{s}}$. The optical fiber was introduced and the root canal was irradiated in apical and middle thirds for $5 \mathrm{~s}$.

Unlased group (6 root canals): Areas with smear layer and debris composed of pulp remants and dentin were observed (Fig 1). Only one of the six specimens showed a clean root canal (Fig 2). Lased group (6 root canals): In the apical third, all of the canal walls were observed with melted dentin (Figs 3-4). Two specimens in the middle third were covered by residual debris.

\section{References}

[1] Y. Kimura et al. Apical Leakage of Obturated Canals Prepared by Er:Yag Laser. J Endodon 2001;27:567-9.

[2] V. Armengol et al. Temperature rise during Er:YAG Laser and Nd:YAP Laser Ablation of Dentin. J Endodon 2000;26:138-141.

[3] R. Yamazaki et al. Effects of Erbium, Crhomium:YSGG Laser Irradiation on Root Canal Walls: A Scanning Electron Microscopic and Thermographic. J Endodon 2001;27:9-12.

[4] The aid of Larruz Serrano J. Paola, Martínez Matamoros Alejandra, Ventura Benitez Rodolfo, Francisco Pasos Nájera and Guadalupe Yescas Díaz is gratefully acknowledged. 


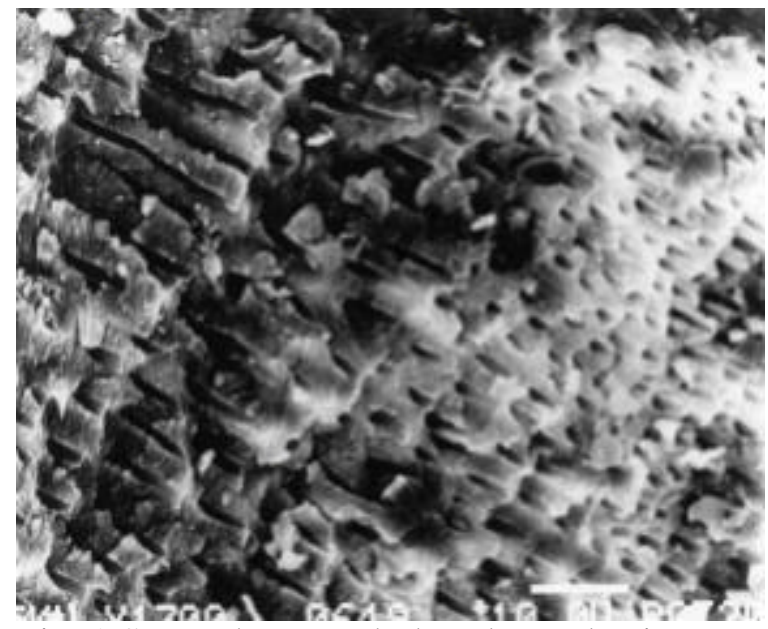

Fig. 1 SEM Photograph that show dentin tubules with debris of unlased specimen. (magnification X 1300)

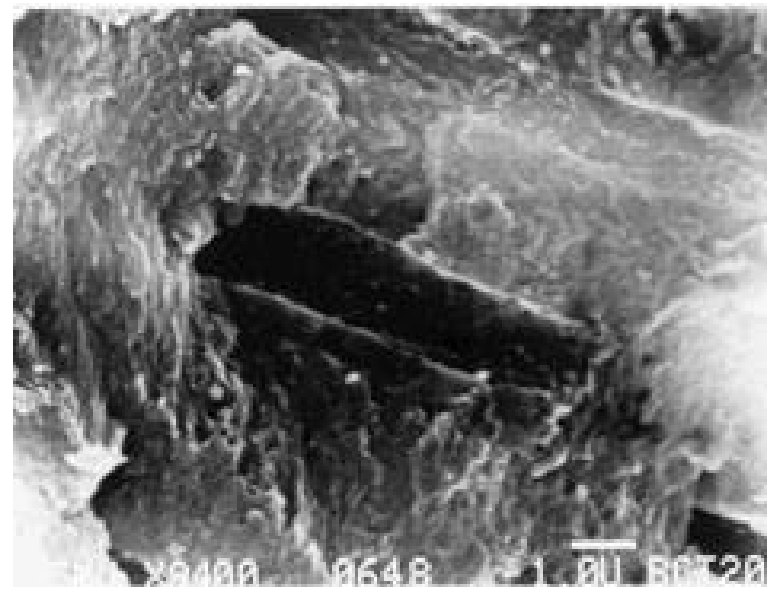

Fig. 3 Micrography that show a tubule of

lased group with melted surface free of debris. melted surface (magnification X 1300). (magnification X 9400).

Fig. 2 Unlased specimen in the apical third.

No debris and smear layer were seen at the root canal wall (magnification X 1300)

Fig. 4 Specimen of lased group with
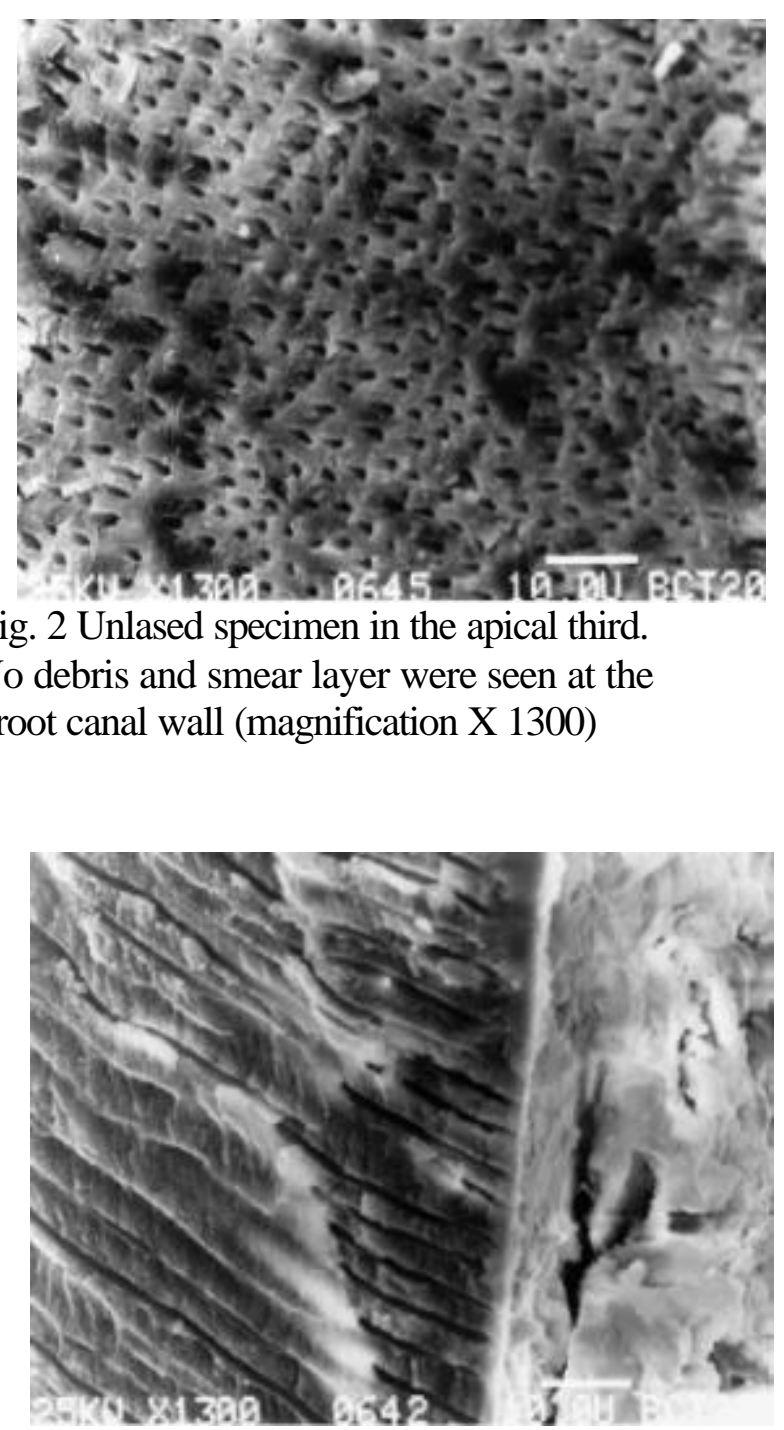